\title{
Peculiarities of distance learning in higher education: The teacher's functions as a chat communication organizer
}

Elena V. Maleko a * Nosov Magnitogorsk State Technical University, Magnitogorsk, Russia https://orcid.org/0000-00023811-309X

Yuliya L. Kiva-Khamzina ${ }^{\text {b }}$ - Nosov Magnitogorsk State Technical University, Magnitogorsk, Russia https://orcid.org/00000002-0711-0240

Natal'ya A. Rubanova c - Nosov Magnitogorsk State Technical University, Magnitogorsk, Russia https://orcid.org/0000-00027407-864X

Elena V. Karpova ${ }^{d}$ - Nosov Magnitogorsk State Technical University, Magnitogorsk, Russia https://orcid.org/0000-00021879-7084

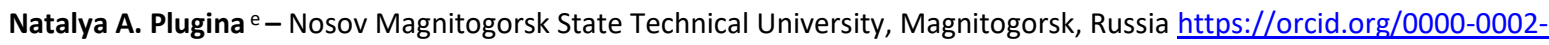
4028-0663

Alexey Yu. Trutnev ${ }^{f}-$ Chelyabinsk region state educational institution of higher education, Magnitogorsk State Conservatory (academy) named after M.I. Glinka, Magnitogorsk, Russia https://orcid.org/0000-0002-1885-1300

\section{Suggested Citation:}

Maleko, E.V., Kiva-Khamzina, Y.L., Rubanova, N.A., Karpova, E.V., Plugina, N.A. \& Trutnev, A.Y. (2021). Peculiarities of distance learning in higher education: The teacher's functions as a chat communication organizer. Cypriot Journal of Educational Science, 16(1), 341-357 https://doi.org/10.18844/cjes.v16i1.5533

Received from April 25, 2020; revised from December 15, 2020; accepted from February 15, 2021.

${ }^{\circ} 2021$ Birlesik Dunya Yenilik Arastirma ve Yayincilik Merkezi. All rights reserved.

\begin{abstract}
The purpose of this article is to define the functions of the teacher as the organizer of chat communication, which has become one of the foundations of Internet communication. The leading method for the study of this problem is the method of situational modeling, which allows considering chat-communication as a process of new social interaction, requiring the leading role of the teacher-organizer, ensuring the maximum involvement of all participants-communicators in this process in order to assimilate new knowledge by the perceiver (learners). This article presents new methodological methods of teacher's work within the framework of chat-communication, defines the important functions of a teacher, who communicates knowledge in the changed socio-cultural environment. The presented methodological material is designed to help teachers of higher education to use chat-communication as a new channel of knowledge transfer from a teacher to a student to adapt to the new communicative realities, to give awareness of the continuity of the educational process, even in a situation of significant changes in conditions of its implementation.
\end{abstract}

Keywords: distance learning, higher education, internet communication, chatting, teacher functions

* ADDRESS FOR CORRESPONDENCE: Elena V. Maleko, Nosov Magnitogorsk State Technical University, Magnitogorsk, Russia E-mail address: elena.maleko@yandex.ru / Tel.: 8(3519)298544 
Maleko, E.V., Kiva-Khamzina, Y.L., Rubanova, N.A., Karpova, E.V., Plugina, N.A. \& Trutnev, A.Y. (2021). Peculiarities of distance learning in higher education: The teacher's functions as a chat communication organizer. Cypriot Journal of Educational Science, 16(1), 341-357 https://doi.org/10.18844/cjes.v16i1.5533

\section{Introduction}

2020 completely changed the process and structure of the educational process. In the context of a pandemic and the spread of COVID-19, there is a disruption threat for previously developed and implemented educational programs (Ivanova, 2020). The self-isolation proposed by the governments of the states turned out to be a necessity in the framework of preventing a deadly infection, but, at the same time, the lockdown disrupted the usual life of the society, paralyzed production, business, and transport systems. In this situation, education required an instant response, which was expressed in a change in the educational platform. At the moment when direct contact between the teacher and the student became impossible, education moved to a distance environment (Bukhtiyarova \& Zubova, 2017; Minakhmetova et al., 2017; Sishchuk et al., 2020).

A solution to the force majeure situation has been found, but at the same time a serious problem has arisen due to the circumstances. It lies in the fact that distance learning has never before been perceived as a full-fledged replacement for 'contact' education, where the teacher interacts directly with the learner. The analysis of the studies related to this problem shows that the use of distance learning is often seen only as a forced measure. It is also believed that learners in a distance format will not be able to obtain the full amount of knowledge planned for in the educational programs of secondary, secondary vocational and higher education. It may be argued that scholarly works on the issue of interest to us are mainly built on the principles of comparative and comparative analysis of distance and contact learning. The most frequent view is that distance learning is formal, partial, and incomplete. Such a view is held, for example, by M.V. Vakulenkova, (Vakulenkova, 2019), O.V. Murashova, S.A. Solovyova (Murashova, Solovyova, 2015). This position is also close to T.A. Olkhova and O.V. Prikhodko. These authors especially point out the unacceptable increase in the burden on the learner, as the share of his/her independence in mastering new educational material in a distance format increases significantly (Olkhovaya, Prikhodko, 2020).

The academic community has expressed dissatisfaction with distance learning, unwilling to acknowledge that this pedagogical practice has become a reality of today's times.

Thus, in Russia, special amendments have been made to the law "On Education", approved by the President of the Russian Federation V.V. Putin on June 8, 2020. Art. 16 explain the essence of distance education as a process that takes place with the use of special distance educational programs and technical means. The adopted amendments to the law emphasize that distance learning is carried out at home on a computer via a telecommunications network (Internet). In this regard, M.N. Bulaeva, A.V. Gushchin, I.R. Voronina note that the amendments made to the legislation allow distance learning to be recognized as an alternative and, at the same time, equivalent to "contact" learning, carried out using the classroom stock of educational institutions (Bulaeva, Gushchin, Voronina, 2020).

It should also be noted that the recent amendments to the Law on Education have not only approved the distance format of the pedagogical process, but also revealed additional problems in its organization (Kiva-Khamzina, 2015), (Rubanova, 2015). Thus, distance education invariably requires high technical equipment of citizens, availability of Internet communications for all users, which in reality is not yet achievable, according to N.L. Yugova (Yugova, 2010). The results of monitoring of the situation conducted by M.A. Polyakova and E.Y. Churilova shows complete dissatisfaction of the society with distance education. These authors are of the opinion that consumers of educational services are most dissatisfied with the teacher's distance from the audience (Polyakova, Churilova, 2017). Another researcher - G.S. Chuchkova draws special attention to the lack of emotional contact and loss of individual approach to each learner, distracted attention when assessing the actions of mentees by the 
teacher, which is caused by the "fragmentation of the picture" on the monitor when using any educational platform (Chuchkova, 2007). The biggest resentment of a number of authors is the lack of direct contact between the learner and the teacher when communicating mediated by the monitor screen (Gryaznova, Bryzgalova, Izmestieva, Nikolaeva, 2018).

In general, we have to acknowledge the fact that the study of existing problems of distance learning by different authors is mainly limited to its criticism. The majority of scientific works lack constructive suggestions on how to improve teacher-learner interaction within the framework of Internet communication. They do not present new forms and methodological techniques applicable in pedagogical practice for productive implementation of distance education.

In order to solve the problem, we would like to clearly state our position. For us, it is that distance learning is now the only way out of a situation where humanity is facing a serious global problem. Its solution should not stop the general development, the acquisition of new knowledge, and therefore it is necessary to subordinate the teaching methodology to the new conditions of the educational process. In our opinion, it is especially important to preserve the dialogical structure in the relationship "teacherstudent", "question-answer" interaction, within which the main thing takes place: the transfer of experience and knowledge even in conditions of Internet communication. Using the example of the educational process in higher education, we would like to show the need for the introduction of new methodological techniques in the framework of the chat-communication between the teacher and the student as the most common form of dialogue in the context of distance education (Sharikova \& Martel, 2012). We believe that the chat communication is the only dialogical form of Internet communication in which the interaction of the teacher and the student is preserved, however, the principles of this interaction change the separation of the sides by the monitor screen. The monotony of the "questionand-answer" dialogue, in our opinion, must be overcome by pedagogical innovations, the use of which changes the teacher's functions as an organizer of chat communication. Mastering new methods of distance learning is now becoming the key to its success and a necessity dictated by the modern sociocultural situation (Ermishin \& Shastina, 2020). For a modern teacher, it is important to master such methods of distance education that would destroy the opinion about its "surrogate" in relation to the traditional educational process. Distance education in all its forms should become a full-fledged replacement for contact classroom training in situations where the latter is not possible.

\section{Materials and Methods}

\subsection{Methods}

The leading method of research into the problem of interest is the method of situational modeling, which allows us to consider chat communication as a process of new social interaction, requiring the leading role of a teacher-organizer, ensuring maximum involvement of all communicating participants in this process in order to assimilate new knowledge by the perceiving side (students). In the process, theoretical methods were also used (analysis; synthesis; specification; generalization). It was important to turn to empirical methods (studying the experience of educational organizations, pedagogical observation). Experimental methods (ascertaining, forming, and control experiments) made it possible to substantiate the practical significance of introducing new pedagogical techniques into the organization of chat communication between a teacher and students.

\subsection{Experimental Basis for the Research}

The experimental base of the study was the Federal State Budgetary Educational Institution of Higher Education Nosov Magnitogorsk State Technical University. 
Maleko, E.V., Kiva-Khamzina, Y.L., Rubanova, N.A., Karpova, E.V., Plugina, N.A. \& Trutnev, A.Y. (2021). Peculiarities of distance learning in higher education: The teacher's functions as a chat communication organizer. Cypriot Journal of Educational Science, 16(1), 341-357 https://doi.org/10.18844/cjes.v16i1.5533

\subsection{Stages of the Research}

The research was carried out in three phases.

At the first stage the problem of teacher-student interaction that arose as a result of forced changes in approaches to teaching under conditions of the pandemic and the spread of COVID-19 was identified and comprehensively considered; the analysis of existing approaches proposed in pedagogical scientific literature was made; the relevance, purpose, and methods of research were justified, the plan of experimental research was made.

The data listed above were collected, analyzed and summarized by the teachers involved in the pilot study. The main materials for the pedagogical experiment were obtained from the courses "Cultural Studies" and "Jurisprudence", which during the pandemic were transferred to a distance learning format. A serious study of the situation was required, as higher education lecturers noted a significant drop in academic performance and in the level of student organisation in their classes. These alarming indicators were identified through direct pedagogical observation.

At the second stage, a model of the formation process of the main functions of the teacher, situational models of teacher-organizer actions of the chat-communication were developed; the features of pedagogical rhetoric, communicative skills of the teacher were identified and justified; experimental work was carried out, the conclusions were analyzed, checked and refined.

The model of the process of formation of the main functions of a teacher as an organizer of chatcommunication in the conditions of distance learning in higher education included two interrelated components:

- socio-cultural component, which reflects the changes in the modern socio-cultural situation and, as a consequence, the educational environment;

- pedagogical component, the formation of which is a response, a natural response to the changing socio-cultural conditions.

The socio-cultural component predetermined the goal of teachers' actions in the changed conditions: formation of the teacher's organizational skills in the conditions of Internet communication. This goal needed to be specified in the steps that were necessary to achieve it. The content of the objective consists in the formation of:

- teacher's personal attitude system for improving the quality of distance learning;

- organizational knowledge, skills, pedagogical rhetoric in the area of chat-communication;

- abilities to self-control, to self-organization in the implementation of teaching functions in the sphere of chat-communication.

The pedagogical component, as an integral part of the experimental model, is also represented in the system of practiced teaching actions. It implies active methodological activities and formation of new teaching functions; obligatory monitoring of chat-communication performance by a teacher; joint monitoring of study sessions by a teacher and learners in order to improve distance learning process in higher education.

A number of criteria that reveal purposefulness, effectiveness and organization of teacher's actions allow evaluating the formation of pedagogical component within the experimental model. 
The final link of the whole model is the result of all the actions described above, which consists in the formation of teaching functions and skills in the framework of chat-communication implementation, in the overall improvement of distance education system.

In the third stage the experimental work was completed, the theoretical and practical conclusions were clarified, and the obtained results were summarized and systematized.

\section{Results}

\subsection{Structure and content of the model}

Based on the system-activity approach, a model of the formation process of the teacher's main functions as of a chat-communication organizer in the conditions of changing socio-cultural situation and appeal to distance learning in higher education was developed. The scientific and pedagogical development includes several components. The motivational-target component of the new model of chat-communication is related to the personal interest of teaching staff in improving the quality of education, the search for new forms of teacher-student interaction within online communication, which has become an organic component of the distance learning process. The content-process component of the model assumes formation of psychological and pedagogical knowledge in a teacher, gradual mastering of a set of communicative skills required in conditions of distance communication with learners. The results-evaluation component implies analysis of the results and their correction. These components of the model in interaction reveal the specifics of the formation of organizational skills of a teacher in conditions of chat-communication with learners. The result of the presented model functioning is understood as the formation of organizational and communicative skills of a teacher within the framework of chat-communication implementation, which is determined by the need to improve distance education in general (Figure 1). 

education: The teacher's functions as a chat communication organizer. Cypriot Journal of Educational Science, 16(1), 341-357 https://doi.org/10.18844/cjes.v16i1.5533

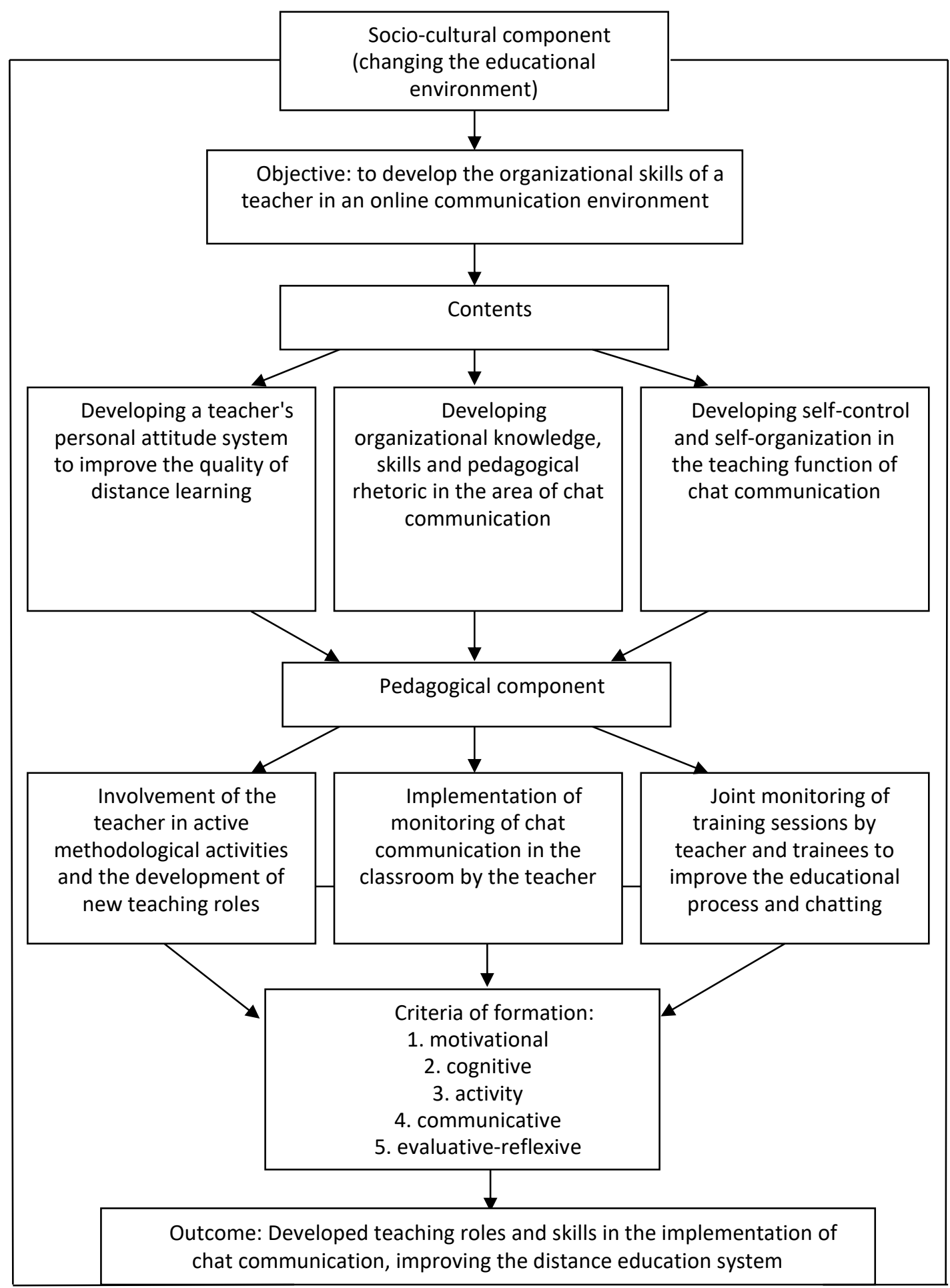

Figure 1. A model of the process of forming the main functions of a teacher as a chatcommunication organizer in a distance learning environment in higher education 

education: The teacher's functions as a chat communication organizer. Cypriot Journal of Educational Science, 16(1), 341-357 https://doi.org/10.18844/cjes.v16i1.5533

The presented model is the formation basis for the organizational communicative skills of a higher school teacher in the conditions of his real teaching activity, which is especially relevant in the context of global socio-cultural changes, which entailed the modernization of the education system.

\subsection{Stages of model implementation}

The implementation of this model involved the following stages of the experimental work:

- determination of the initial level of formation of teachers' communicative skills with the use of questionnaire survey methods, pedagogical observation and self-observation, statistical processing of the research results.

- development and implementation of scientific-methodical support, contributing to the successful construction of Internet communication in the classroom within the developed model of the process of forming the main functions of the teacher as an organizer of chat-communication in the conditions of distance learning in higher education

- identifying the formation dynamics of organizational functions and skills of teachers, improving the quality of training

\subsubsection{Ascertaining Stage}

In total, the study covered 6 teachers of the Department of Law and Cultural Studies of Nosov Magnitogorsk State Technical University, who became direct participants of the experiment.

At the initial stage of the research, all the teachers were questioned, the processing of the results of which made it possible to form an objective idea of the formation level of communication skills in the framework of Internet communication and organization of chat communication with students. The questions of the questionnaire were presented as follows (Table 1):

Table 1. Analysis of the results of the diagnostic survey (questionnaire survey) of teachers in the Department of Law and Cultural Studies during the pilot phase

\begin{tabular}{|c|c|c|c|}
\hline Question & Teachers' responses ( $p$ & rson/\%) & \\
\hline $\begin{array}{l}\text { 1. Do you have } \\
\text { experience of working } \\
\text { in a distance learning } \\
\text { system? }\end{array}$ & $\begin{array}{l}\text { I do not have } \\
\text { (0 pers. / } 0 \% \text { ) }\end{array}$ & $\begin{array}{l}\text { I hold classes as needed } \\
\text { ( } 4 \text { pers. } / 67 \% \text { ) }\end{array}$ & $\begin{array}{l}\text { I am constantly } \\
\text { working in a distance } \\
\text { learning system } \\
\text { ( } 2 \text { pers. } / 33 \%)\end{array}$ \\
\hline $\begin{array}{l}2 . \text { What working } \\
\text { methods do you use in } \\
\text { your distance learning } \\
\text { sessions? }\end{array}$ & $\begin{array}{l}\text { I do not conduct } \\
\text { classes in this form } \\
\text { (0 pers. } / 0 \% \text { ) }\end{array}$ & $\begin{array}{l}\text { Oral communication with } \\
\text { learners by technical } \\
\text { means and chat } \\
\text { ( } 5 \text { pers. } / 83 \% \text { ) }\end{array}$ & $\begin{array}{l}\text { Oral communication } \\
\text { with learners by } \\
\text { technical means, } \\
\text { chat and visualization } \\
\text { methods (slides, } \\
\text { drawings, videos, } \\
\text { etc.) } \\
\text { (1 pers. } / 27 \%)\end{array}$ \\
\hline
\end{tabular}




3. How would you I don't use chat
characterize your chat (0 pers. / 0\%)
communication?

3. How would you I don't use chat communication?

4. Do you think that distance learning is in many ways inferior to "face-to-face" learning?

\begin{abstract}
No possibility to compare different forms of work as I have not worked remotely (0 pers. / $0 \%$ )
\end{abstract}

\section{Result}

\begin{abstract}
Teachers' communication skills in Internet communication and chatting with learners are not formed
\end{abstract}

For me it is a teacherstudent dialogue, answering the questions posed

(6 pers. / 100\%)
Chat is a form of work in which, as a result of a question-andanswer session, the whole group of learners, united by a common subject of study, is involved (0 pers. / 0\%)

Distance learning is not inferior to "contact" learning, where the teacher uses special forms of work applicable to maintain interaction with the learner even through the monitor screen (0 pers. / 0\%)

The teacher's communication skills in Internet communication and chatting with learners are at a high level

(1 pers. / $12.5 \%$ )

(0 pers. / $0 \%$ )

Teachers' communication skills in Internet communication and chatting with students are at an intermediate level

(5 pers. / $87.5 \%$ ) 
Maleko, E.V., Kiva-Khamzina, Y.L., Rubanova, N.A., Karpova, E.V., Plugina, N.A. \& Trutnev, A.Y. (2021). Peculiarities of distance learning in higher education: The teacher's functions as a chat communication organizer. Cypriot Journal of Educational Science, 16(1), 341-357 https://doi.org/10.18844/cjes.v16i1.5533

The experimental stage showed that distance learning, having become a reality of today, requires more attention, which can be expressed in new goal-setting, in the development of new methods and forms of activity.

Higher-education teachers were asked to pay closer attention to the possibilities of chat as a dialogue form in which teacher-student interaction is obligatory. Internet chat is a direct analogue of "contact" dialogue, but it requires a different organizational approach and a different rhetoric, especially when we are talking about a dialogue with a group behind a screen where none of the participants has a real relationship, carrying out their actions only in virtual space.

\subsubsection{Formative Stage}

The development of new methodological techniques in the context of internet communication required active interaction from the teachers involved in the experiment. All participants were invited to get acquainted with the latest scientific and scientific-methodological developments in the field of chat communication and to substantiate their methodological innovation of teaching chat in the Internet space. The theoretical basis for the discussion of methodological proposals in the field of chat communication was the scientific research of A.V. Mogilev (2014), O.V. Murashova and S.A. Solovieva (2015), N.A. Kubrakova (2009), I.O. Kovalevich (2018). These authors presented their scientific and methodological developments in the field of chat communication and mastering of new pedagogical technologies brought to life by distance learning (Gryaznova et al., 2019). Based on the existing scientific research, the teachers of the Department of Law and Cultural Studies proposed their own methodological techniques for conducting chat communication for educational purposes, where special attention was paid to the personality of the teacher who performs the function of an Internet dialogue organizer. As a result of pedagogical observations and synthesis of the scientific and methodical experience already available in the literature, a round table discussion was held on the theme: "Pedagogical innovations in distance learning: the function of the teacher as a chat-communication organizer". As a result of the discussion, the following suggestions were made, which found application in further practice of distance learning.

Chat as a form of a dialogue between a teacher and a learner justifies its existence as it is a very productive form of work. Chat can be used for discussion, questioning, exchange of opinions, heuristic dialogue, etc. Chat is possible on any online educational platform, so it is ideal for distance learning. Even if the technical devices of the interacting parties are not equipped with microphones and webcameras, chatting is very fruitful in written (typed) format.

The main thing a teacher should avoid during a chat session is monotony, which leads to loss of interest and scattered attention of the learners. The question posed by the teacher is addressed to all the participants in the chat room. Each learner is expected to answer it. However, chat requires a sequence of answers to be reproduced on a technical device and perceived by the teacher, and therefore, if there are 25-30 students in a group, the answer to one question may drag on until the end of the lesson. In this case, those who have already answered the question are out of the teacher's sight, "dropped out" of Internet communication. It should be kept in mind that conditions of e-chat are very different from those of face-to-face teaching. In 'contact' learning, things are different: the participants can add to the most relevant answers, actively express their agreement or disagreement with the person who answered first. In this case, the "contact" dialogue becomes emotionally fluid, engaging those who have not yet participated. Chat is organized differently; it assumes a full response from each participant and therefore "drags on", often not allowing not one but a number of questions to be addressed in one session. This is why the roundtable participants agreed that there should be other methodologies specifically designed for distance learning in order to organize chat sessions. 

education: The teacher's functions as a chat communication organizer. Cypriot Journal of Educational Science, 16(1), 341-357 https://doi.org/10.18844/cjes.v16i1.5533

Functions of the organizer teacher. The involvement of the learners in the chat is entirely up to the teacher. It is important for the teacher to keep everyone's attention, even when the participants are distant from each other. Undoubtedly, chatting requires the full concentration and attention span of the facilitator. A teacher who organizes chat-communication should know his/her subject to the fullest extent, be ready to give an exhaustive answer to any question arising in a chat. He/she should write correctly, without spelling and punctuation errors, be able to type fast, to react immediately to a changing situation of communication. It is the teacher who keeps the interest and activity in the chat room. In order to do so, he/she needs to perform the following functions:

- "complimentary" function is to create a positive background at the beginning of communication, to base his own rhetoric only on polite references, to celebrate positive moments, to praise and compliment learners, to prevent conflicts between chat participants in every possible way;

- the function of "prompting the virtual audience" to active thought-response activity - ask problematic or provocative questions that many learners will want to refute, and the sequence of responses in the chat room will give them more time to think about it;

- a 'dialogue engagement' function: conducting polls or blitzes where a short, quick answer is sufficient to indicate a dialogue participant's position;

- the function of "increasing competitiveness" of participants by organizing quizzes and contests which imply that students react quickly and try to be the first and most accurate in their answers.

It is beyond argument that it is up to the teacher to decide how 'lively' the chat communication will be, how significant each participant's opinion will be and how much learning material will be absorbed. The complexity of the teacher's organizational role in chat communication lies in the fact that he or she has to create the effect of close interaction among all the participants separated by the Internet space.

The participants of the round table prepared methodological developments and proposed for general consideration variants of learning chat rooms, which, in their opinion, should become the most popular in distance learning practice.

Chat personal tuition is a very simple but necessary form of Internet communication. The students ask the teacher questions in writing (by typing the question and sending it to the chat room) or using a microphone, but in this case the teacher duplicates these questions in the chat room. Answers to the questions asked are also typed by the teacher on the keyboard, so that the participants of the chatconsultation can go back to the material, repeat what they may have missed. In this case, the students are unlikely to duplicate questions that have already been asked, as both the questions and their answers are strictly recorded. The trainees can discuss the answers given by the teacher among themselves and directly with the teacher organizing the chat.

Despite the simplicity of this form of chat, it is quite difficult to attract the attention of the whole group of learners to this form of work. Not all participants will be able to join the chat session at the same time (there may be technical or personal obstacles), not all learners will stay until the end of the session and therefore they will miss some of the information.

In order to work fruitfully during a chat session, it is necessary to use the pedagogical technique of increasing the motivation of the trainees to participate in the chat session. A chat session is best carried out with a close-knit team in which the organization of the learners is high.

Chat discussion. This form of chat communication can be used for seminar sessions. All participants in the chat room can ask and answer questions. However, in this state of affairs, chat communication 

education: The teacher's functions as a chat communication organizer. Cypriot Journal of Educational Science, 16(1), 341-357 https://doi.org/10.18844/cjes.v16i1.5533

can become a 'chaos of opinions', in the midst of which the purpose of the learning chat will be forgotten. This is why the function of the facilitator is especially important in a chat session. He/she should define in the chat the range of issues to be shared and set a time limit for the discussion of the learning material within each issue. The teacher should encourage the students to respond and, at the same time, limit their time. All responses should be summarized and channeled in a constructive way in order to address the issue as fully and comprehensively as possible. The general rhetoric should be friendly and correct.

In order to organize a chat-discussion (seminar class), the teacher should announce in advance the topic and the range of problems to be discussed. The participants should be familiarized in advance with the textbook on the general topic of discussion. An important pedagogical technique for conducting a chat-discussion is to increase the authority of the organizer-teacher who, thanks to his knowledge and qualifications, should regulate the process of discussion without allowing it to go in a different, unplanned direction.

Chat examination (credit). The organizer of the chat room (teacher) quizzes participants on the course, asking questions that require answers based on the material covered earlier. The questions asked during the chat may be known to the participants in advance, or may only be asked during the chat session itself. The examiner can openly evaluate and comment on the answers received. In this case it is important to consider the speed and objectivity of these answers, as a quick and accurate response from a student indicates a firm grasp of the training material.

It should be noted that a chat examination (credit) is the most technically difficult to organize. Parallel to participating in chat, learners can use other electronic tools where they can find hints. That is why the ideal situation for such a chat would be the possibility of conducting it using a webcam, with the widest possible view on the part of both the teacher and the learner.

The exam (test) itself plays the role of a motivator for the student. The teacher serves as the organizer and the main controlling person, for whom it is important objective judgment and assessment of the student's answer.

As a result, the round table and the discussion of new methodological approaches to the organization of chat communication made it possible to look at the specifics of distance learning in a different way. The teachers involved in the experiment changed their general attitude towards the distance learning process. The effectiveness of the study sessions became associated with the use of constructive methodological forms and new pedagogical techniques. In the course of joint analysis and evaluation of the completed work, both from the teacher's side and from the learner's side, the difficulties were discussed, a substantive and detailed description of the results of the learning activity was given, the advantages and disadvantages of the completed work were analyzed. This allowed the teacher to correlate his/her own assessment of the students' achievements with their self-assessment and to make timely corrections to what needed to be changed.

\subsubsection{Control Stage}

At this stage of the experiment to determine the level and identify the formation dynamics of communication skills in the framework of Internet communication and organization of chat communication with students a diagnostic cross-section was carried out using the same methodology as at the ascertaining stage of the experiment. The data of the control cut showed changes in comparison with the results of the ascertaining experiment for all the criteria. 

education: The teacher's functions as a chat communication organizer. Cypriot Journal of Educational Science, 16(1), 341-357 https://doi.org/10.18844/cjes.v16i1.5533

The situation with the dissemination of COVID-19 led to the widespread introduction of distance forms of work. All the teachers engaged in the experiment were involved in the process of distance learning with the obligatory use of Internet chats as part of teaching courses. That is why the motivation to master new forms of work and improve them in order to improve the quality of education has increased.

The analysis of the results of the diagnostic survey at the control stage allowed us to conclude that the majority of teachers of the department (82.5\%) eventually formed a high level of communication skills in the framework of Internet communication and organization of chat communication with students.

Focused work and general formative impact resulted in changes in the following criteria of chat communication as a type of Internet communication:

1. Motivational - there was an awareness of the inevitability and necessity of each teacher's involvement in the distance learning process. The continuity of educational trajectories now directly depends on how mobile each of the participants in the educational process can rearrange their actions depending on the changes in the socio-cultural situation.

2. Cognitive - expressed in new ways of knowledge translation and assimilation. Obtaining knowledge remotely has confirmed the new capabilities of the educational system in the minds of faculty and students. The main channel for knowledge transfer is still the communication between a teacher and a student, but its implementation has now taken on a new format - Internet communication.

3. Active - distance learning has invariably required new types of learning activities. Chatcommunication has become a new way of interaction between a teacher and a student, which allows carrying out various forms of work: consultations, seminars in the form of chat-discussions, intermediate and final control in the form of a chat-exam or a chat-credit.

4. Communicative - required special attention to pedagogical rhetoric. There was awareness that verbal (written) communication plays a major role in chat communication and therefore requires participants to be lexical, spelling and punctuation literate. In this case, there is an inevitable mastery of subject terminology by learners, which facilitates the formulation of the most accurate answers to the teacher's questions. An idea of special chat-rhetoric is formed: laconic, maximally precise, terminologically rich, complimentary, situational, and directed at a specific addressee - participant of the communication process.

5. Evaluative-reflexive - the process of communication of a teacher and a learner was now considered by each of the experiment participants from the evaluative positions: the productivity of chat communication and its shortcomings were analyzed and their reasons were identified. The student audience opinion on the effectiveness of chat communication became important for each tutor. The reflection on the part of the students helped to overcome the difficulties arising in the process of Internet communication (the requirement of quick reaction in the dialogue, the requirement of precise wording in the answers, conciseness, absence of non-verbal characteristics in the chat content, etc.).

When communicating with colleagues, all the experiment participants expressed an opinion about the particular relevance of the new forms of work in the distance learning process. There was a willingness to carry out further methodological work about the improvement of chat communication as an important channel for knowledge transfer in the current situation. The view on distance learning has changed, which should be organized in the most comfortable environment for the dissemination of 
Maleko, E.V., Kiva-Khamzina, Y.L., Rubanova, N.A., Karpova, E.V., Plugina, N.A. \& Trutnev, A.Y. (2021). Peculiarities of distance learning in higher education: The teacher's functions as a chat communication organizer. Cypriot Journal of Educational Science, 16(1), 341-357 https://doi.org/10.18844/cjes.v16i1.5533

education in the context of the technology development, the transformation occurring in the sociocultural space.

The analysis of the formation dynamics of teaching skills in the experimental group gives reason to believe that the implementation of the developed model makes it possible to significantly increase the efficiency of the distance education process.

\section{Discussions}

The study of scientific and pedagogical works of recent years allows us to state that there are no special studies devoted to the problem of teacher's function formation as an organizer of chatcommunication, which has become one of the foundations of Internet communication in the conditions of real practical pedagogical activity carried out remotely. The explanation for this can be found in the fact that the problems of distance learning became especially evident only in 2020 in the conditions of the pandemic which paralyzed the life of the society. It was during this period that educational activities were almost entirely transferred to the Internet format, which required an update of all forms of pedagogical work. We can say that the consideration of Internet communication is still not presented in the pedagogical plane, as the attention of researchers is mainly focused on the technical, linguistic or organizational aspect of consideration of this field of study.

Thus, before 2020 and in the current period, research papers on distance education have been published quite frequently. However, they are mostly aimed at studying the information environment itself: they present a comparative characteristic of distance learning systems (Afanasyeva, 2016), consider the means of technical support of information work (Denisova \& Lehanova, 2020), organize elearning in a modern university (Olkhovaya \& Prikhodko, 2020). That is why the organizational and technical aspect becomes predominant in these studies.

The practice of distance communication is also subject to scientific discussion. We are talking about language economy in the system of computer communication (Kosheleva \& Kirillova, 2013; Sohan \& Khorunzhaya, 2015), punctuation and graphic design of printed electronic utterance (Lugovskaya, 2020), about correlation of Internet communication with spoken speech (Kubrakova, 2009). That is why the general thrust of scientific works in the field of Internet communication seems to be linguistic, generallanguage, which in no way connects these studies with pedagogical foundations of distance education.

Quite a few research works are devoted to chat-communication, but the linguistic and general linguistic aspect becomes the most discussed in them as well. At the moment we can point to studies in which Internet chat is considered as a linguistic genre (Wang, 2017), it is presented as a dialogic structure of speech (Murashova \& Solovieva, 2015), as a special form of personality representation in Russian-language discourse (Zavyalova \& Tikhonova, 2015). The study of the general linguistic foundations of Internet chat does not connect it with pedagogical rhetoric, but it is this aspect within the distance education process that is especially relevant for contemporary consideration.

The proposed research paper is the first to examine the use of Internet-chat in real pedagogical conditions determined by the total introduction of distance education into sociocultural practice in connection with the spread of COVID-19, which makes it possible to present this electronic dialogical form of teacher-student work as an innovative one. We understand Internet-chat not only as a questionand-answer unity, which is built as a result of distance communication, but also as a promising form of work in conditions of Internet communication, thanks to which it is possible to organize consultation, discussion work, checking the students' knowledge in the process of intermediate and final attestation. 

education: The teacher's functions as a chat communication organizer. Cypriot Journal of Educational Science, 16(1), 341-357 https://doi.org/10.18844/cjes.v16i1.5533

We especially emphasized the organizing function of the higher school teacher, who arranges Internet-chat in accordance with the specific pedagogical tasks that are set in each training session. At the present stage of educational development, it is becoming clear that the distance format introduces additional difficulties in the implementation of the knowledge exchange process. That is why the need to find new forms of work, to change the methodological practice of teaching disciplines in higher education (Maleko et al., 2018; Karpova, 2018) has arisen. The teacher assumes the role of an organizer of the virtual classroom, which is behind the monitor screen. In this case, a meaningful empathic beginning of the educational process is lost, which may lead to a complete loss of coherence of the participants of the educational process. We believe that any pedagogical search in distance learning should be as much as possible aimed at achieving interaction between a teacher and a learner, at attracting and holding the attention of an audience that perceives new knowledge and experience. In our opinion, Internet-chat has all the above-mentioned possibilities, and that is why modern teachers of higher education, building the process of virtual communication with their students, should pay the closest attention to it.

Separately, we should note that modern pedagogy constantly faces the problem of personality formation in the space of information culture (Maleko, 2018). There is no doubt that the ideal of the young generation is a free person (Slobodnyuk et al., 2020), devoid of restrictions in communication, in their own choice of life position. The availability of online education, the possibility of permanent professional development and, therefore, of social significance, increasingly reinforces this position. At the same time, internet communication involves the younger generation in a globalizing socio-cultural space (Orekhovskaya et al., 2018) in which community unity in reality acquires virtual forms. However, it is important to understand that the most complex problems of modern society - environmental (Tavstukha \& Korzhanova et al., 2018), problems of intercultural relations (Podymov et al., 2018), interaction of man and technology, etc. now must be solved in the form of dialogue. Internet chat is able to prepare dialogical thinking, which is built in the context of interaction, tolerance, formation of a positive attitude to a different opinion, different from one's own position. The higher education teacher in this regard has an important function, which is not only to form knowledge, skills and abilities, but also to prepare students for the socio-cultural dialogue necessary for the formation of sustainable social relationships.

\section{Conclusion}

The paper establishes that the use of chat communication in the conditions of COVID-19 proliferation and the process of general transition of educational organizations to distance learning is a new form of pedagogical work, which forms dialogical thinking. The practice of organizing Internet-chat is necessary for a higher school teacher as a directed overcoming of disconnection between a teacher and a learner, arisen as a result of the forced social distancing. The use of internet chat in pedagogical practice requires the higher education teacher to perform a number of functions that reinforce the interaction process. These include the 'complimentary' function, the function of 'inducing a virtual audience' to active thought-response activity, the function of 'engaging in dialogue', the function of 'enhancing competitiveness' of Internet chat participants. In this case, Internet-chat itself is perceived as an innovative form of work, enabling the organization of different types of classes and the realization of a variety of pedagogical goals.

The materials of this article can be useful for the higher school teachers adapting to the new conditions of professional activity in the sphere of distance education, for the specialists in the sphere of Internet-communication, aiming to develop programs which give an opportunity to improve the education quality. 

education: The teacher's functions as a chat communication organizer. Cypriot Journal of Educational Science, 16(1), 341-357 https://doi.org/10.18844/cjes.v16i1.5533

In the process of work, new questions and problems emerged which need to be solved in the practice of modern research. For example, chat-communication is already being replaced by chat-bots replacing the personality of the teacher-organizer from the pedagogical process. In this case the question arises as to whether the computer program can fully replace the communication with the teacher. Assessing the pros and cons of these technical innovations in contemporary educational practice could be a separate topic of pedagogical research.

\section{References}

Afanasyeva, M. A. (2016). Comparative characteristics of distance learning systems used in higher education. Postulat, 3(3), 16-23 (in Russ.).

Bukhtiyarova, I. N., \& Zubova, O. G. (2017). Distance technologies as a new educational practice. Bulletin of Contemporary Studies, 3(6), 60-63 (in Russ.).

Bulaeva, M. N., Gushchin, A. V., \& Voronina, I. R. (2020). Opportunities of distance learning technology in higher education. Azimuth of Scientific Research: Pedagogy and Psychology, 9(33), 48-51 (in Russ.).

Chuchkova, G. S. (2007). On the problem of communication in virtual communicative environment. Omsk Scientific Bulletin, 1(51), 90-94 (in Russ.).

Denisova, O. A., \& Lehanova, O. L. (2020). Digital tolerance of information environment: means to ensure in the period of pandemic. Problems of Modern Pedagogical Education, 67(4), 130-133 (in Russ.).

Ermishin, A. S., \& Shastina, E. M. (2020). Application of interactive teaching methods in distance learning process. Actual problems of psychology and pedagogy in modern education: Collection of scientific articles of IV International Scientific-Practical Conference. (66-68). Yaroslavl: Yaroslavl State Pedagogical University. K.D. Ushinsky (in Russ.).

Galchenko, N.A., Shatskaya, I.I., Makarova, E.V., Kulesh, E.V., Nizamutdinova, S.M., Yudina, A.M., Skutelnik, O.A. (2020). Student hood spiritual needs in self-isolation period: Features and ways to meet them. EurAsian Journal of BioSciences, 14(1) 2229-2234 (in Russ.).

Gryaznova, E. V., Bryzgalova, Y. V., Izmesteeva, N. V., \& Nikolaeva, L. Y. (2018). On the nature of distance education. Azimuth of Scientific Research: Pedagogy and Psychology, 4(25), 169-172 (in Russ.).

Gryaznova, E. V., Treushnikov, I. A., Bobykina, N. Y., \& Afanasyev, S. V. (2019). Distance pedagogy: problems of conceptualization and definition. Azimuth of Scientific Research: Pedagogy and Psychology, 4(29), 63-65 (in Russ.).

Ivanova, O. N. (2020). Distance learning in the COVID-19 pandemic. Advances in the Humanities, 10, 18-22 (in Russ.).

Karpova, E. V. (2018). Modern interactive technologies of teaching legal disciplines. Traditional national-cultural and spiritual values as the foundation of innovative development of Russia, 2(14), $27-29$ (in Russ.).

Kiva-Khamzina, Y. L. (2015). Civil-legal protection of rights in the sphere of culture and education. Traditional national-cultural and spiritual values as the foundation of innovative development of Russia, 2(8), 80-82 (in Russ.).

Kosheleva, O. N., \& Kirillova, T. S. (2013). Language economy in the system of computer communication. Modernization of science and education. Opportunities. Problems. Prospects. Proceedings of the AllRussian conference. (103-106). Chelyabinsk: IP Obzhorin A.M. (in Russ.).

Kovalevich, I. O. (2018). Pedagogical technologies in conditions of distance education. January pedagogical readings, 4(16), 7-11 (in Russ.). 
Maleko, E.V., Kiva-Khamzina, Y.L., Rubanova, N.A., Karpova, E.V., Plugina, N.A. \& Trutnev, A.Y. (2021). Peculiarities of distance learning in higher education: The teacher's functions as a chat communication organizer. Cypriot Journal of Educational Science, 16(1), 341-357 https://doi.org/10.18844/cjes.v16i1.5533

Kubrakova, N. A. (2009). Chat-communication and colloquial speech (on the example of Russian and English). Philology and Man, 2, 140-145 (in Russ.).

Lugovskaya, E. G. (2020). Punctuation-graphic design of speech VS efficiency of chat communication. Language and speech in Internet: personality, society, communication, culture: collection of articles of the IV International Scientific-Practical Conference: in 2 volumes. (120-126). Moscow: Peoples' Friendship University of Russia (in Russ.).

Maleko, E. V. (2018). Peculiarities of personality formation in the space of information culture. Traditional nationalcultural and spiritual values as the foundation of innovative development of Russia, 1(13), 29-31 (in Russ.).

Maleko, E. V., Rubanova, N. A., Karpova, E. V., Akulova, I. S., Khakova, G. S., \& Plugina, N. A. (2018). Applying Innovative Teaching Techniques and Methods, when Teaching Cultural Studies in Higher Education Institutions. Modern Journal of Language Teaching Methods, 8(11), 17-29.

Minakhmetova, A.Z., Skutelnik, O.A., Fedorchuk, Y.M., Shulga, T.I., Pavlushin, A.A. \& Shagiev, B.V. (2017). Motivational and valuable orientation of teachers as a condition to form students tolerant behavior. Man in India, 97(3), 323-332(in Russ.).

Mogilev, A. V. (2014). How to apply chat rooms in teaching? Public education, 5, 180-187 (in Russ.).

Murashova, O. V., \& Solovyova, S. A. (2015). Peculiarities of dialogues in chat communication. In Proceedings: Problems of speech generation and perception. Proceedings of the XIIIth retreat school seminar. Ed. by E.V. Grudeva. (121-128). Cherepovets: Cherepovets State University (in Russ.).

Olkhovaya, T. A., \& Prikhodko, O. V. (2020). Organization of e-learning in modern higher education institution. Modern problems of science and education, 3, 56-63 (in Russ.).

Orekhovskaya, N. A., Galushkin, A. A., Maleko, E. V., Bezenkova, T. A., \& Plugina, N. A. (2018). Globalization and youth: philosophical analysis of challenges and ways to overcome them. XLinguae, 11(2), 256-264.

Podymov, N. A., Sorokina, G. A., Litvinenko, N. A., Kurnykina, O. V., Fabrikov, M. S., Maleko, E. V., \& Novitskaya, L. Yu. (2019). Study on Cross-Cultural Interaction Competency Development of International Students: Permanent Nature of Cultural Archetype. International Journal of Advanced Biotechnology and Research, 10, 162-171.

Polyakova, M. A., \& Churilova, E. Yu. (2017). Blended learning as a learning model for modern students. Modern trends in the development of science and technology: collection of scientific papers on the materials of the International Scientific-Practical Conference. In 5 parts. Ed. by J.A. Shapoval. (166-171). Belgorod: LLC "Agency for Advanced Scientific Research (in Russ.).

Rubanova, N. A. (2015). Topical issues of administrative and legal regulation in the sphere of culture and education. Traditional national-cultural and spiritual values as the foundation of innovative development of Russia, 2(8), 78-80 (in Russ.).

Sharikova, L. A., \& Martel, O. N. (2012). Chat communication through the eyes of a researcher. A collection of SWorld research papers, 41(4), 3-6 (in Russ.).

Sishchuk, J. M., Gerasimova, I. G., Oblova, I. S., Bykowa, E., \& Zheltukhina, M. (2020). Gender effect in postgraduate studies at higher technical institutions in Russia. Austria and the UK. Global Journal of Engineering Education, 22(3), 186-192.

Slobodnyuk, S. L., Kiva-Khamzina, Yu. L., Maleko, E. V., Rubanova, N. A., Karpova, E. V., \& Plugina, N. A. (2020). Free man and talion principle in Russian biblical discourse of the twentieth century. European Journal of Science and Theology, 16(2), 85-94. 

education: The teacher's functions as a chat communication organizer. Cypriot Journal of Educational Science, 16(1), 341-357 https://doi.org/10.18844/cjes.v16i1.5533

Sohan, A. A., \& Khorunjaya, N. V. (2015). Economy of linguistic expression in Internet texts. Lomonosov Readings in Altai: Fundamental Problems of Science and Education: Proceedings of the International Conference. (2930-2933). Barnaul: Altai State University (in Russ.).

Tavstukha, O. G., Korzhanova, A. A., Chistyakov, A. A., Vasilenko, A. S., Chistyakov, K. A., Shatskaya, I. I., Starikova, L. D., \& Maleko, E. V. (2018). Personality Ecological Consciousness: Values Ethical Vector of Nature Safety Sustainable Development. Ekoloji, 27(106), 1355-1364.

Vakulenkova, M. V. (2019). Informatization of education as a key condition for the development of society. Electronic Scientific Journal, 6(26), 11-15.

Wang, D. (2017). Experience of linguistic analysis of the Russian-language Internet chat genre. Culture and civilization, 7(5A), 31-37.

Yugova, N. L. (2010). Information and communication technologies as a means of implementing innovation in education. Pedagogical systems of creativity development: Proceedings of the 9th International Scientific and Practical Conference. Ed. by S.A. Novoselov. (327-330). Ekaterinburg: Urals State Pedagogical University (in Russ.).

Zavyalova, Z. S., \& Tikhonova, G. Yu. (2015). Interactive chat as a special form of being and representation of personality (Russian-language discourse). Siberian Science Bulletin, 2(17), 244-250. 